\title{
Correction to: No need for frame-wise attenuation correction in dynamic Rubidium-82 PET for myocardial blood flow quantification
}

J. D. van Dijk, MSc, PhD (i), ${ }^{\text {a }}$ P. L. Jager, $M D, P h D,{ }^{a} J$. P. Ottervanger, $M D, P h D,{ }^{c}$

C. H. Slump, PhD, ${ }^{d}$ and J. A. van Dalen, $\mathrm{PhD}^{\mathrm{b}}$

a Department of Nuclear Medicine, Isala Hospital, Zwolle, The Netherlands

b Department of Medical Physics, Isala Hospital, Zwolle, The Netherlands

c Department of Cardiology, Isala Hospital, Zwolle, The Netherlands

d MIRA: Institute for Biomedical Technology and Technical Medicine, University of Twente, Enschede, The Netherlands

doi: $10.1007 / \mathrm{s} 12350-019-01680-5$

\section{CORRECTION TO: J NUCL CARDIOL}

HTTPS://DOI.ORG/10.1007/S12350-019-01654-7

Due to the typesetter not carrying out the author's corrections at proof stage, there are two errors in the published article: where " $\mathrm{mL} \times \min \times \mathrm{g}$ " appears, it should be " $\mathrm{mL} / \mathrm{min} / \mathrm{g}$ ".
One error is in the Figure 3 caption, and one error is in the second sentence under the heading "MBF Quantification'.

The original article has been corrected.

Publisher's Note Springer Nature remains neutral with regard to jurisdictional claims in published maps and institutional affiliations.
The original article can be found online at https://doi.org/10.1007/ s12350-019-01654-7.

Reprint requests: J. D. van Dijk, MSc, PhD, Department of Nuclear Medicine, Isala Hospital, PO Box 10400, 8000 GK Zwolle, The Netherlands; jorisvdijk@gmail.com

J Nucl Cardiol 2019;26:746

$1071-3581 / \$ 34.00$

Copyright (C) 2019 American Society of Nuclear Cardiology. 